suitable for natural regeneration of scrub to occur being dioecious, pollination can only occur if male and female plants are growing in close proximity. Seedlings and cuttings are being grown and a programme of planting initiated.

Enclosure projects are being undertaken on several other NTS properties.

\title{
Reference
}

Mardon, D. K. 1990. Conservation of Montane Willow Scrub in Scotland. Transactions of the Botanical Society of Edinburgh 45, 427-36.

\section{Anatomical and morphological microfeatures of the leaf in Salix L. species and their physioecological significance}

\author{
P. Paiero, P. Semenzato and T. Urso \\ Department of Forestry, University of Padua, Italy
}

The willows show the whole range of woody forms: tree forms in warm temperate climates, shrub forms in cold temperate climates and dwarf and prostrate forms in cold climates and arctic zones. The three ecophysionomic types are related to the three subgenera that constitute the genus Salix, Salix, Vetrix and Chamaetia respectively.

The great adaptability of the willows to a large diversity of environmental conditions suggested the presence of physiological adaptations. In studies the fine leaf morphology in some species growing in the Italian Alps were examined.

In most of the species examined some xeromorphic adaptations were found such as:

Thick cuticle and waxy layer on the epidermis.

Mucilages in the walls of the epidermal cell.

Phenolic compounds in the vacuole of the epidermal cells and underlying layers.

Hair and trichomes.

Our observations pointed out a relationship between ecological types and some of the xeromorphic adaptations (waxes).

(a) Warm-climate willows (subgenus Salix) possessed very thick waxes (up to $40 \mu$ ) and hairs

(b) Cold-climate willows (subgenus Chamaetia) possessed thin laminated waxes and no hairs

(c) Temperate-climate willows (subgenus Vetrix) possessed intermediate characters. 